\title{
PLANO CARTOGRÁFICO DO PROJETO PARANAPANEMA
}

O Plano Cartográfico do Projeto Paranapanema, ${ }^{1}$ idealizado em princípios de 1990, rege a execução da cartografia sistemática do Programa de Pesquisas Arqueológicas da Bacia do Rio Paranapanema, Estado de São Paulo - Projeto Paranapanema.

Responsável pelo estudo arqueológico de uma extensão que totaliza $47.475 \mathrm{~km}^{2}$, o Projeto Paranapanema tem, hoje, seu território dividido em regiōes, mesoregiōes e microregiōes compondo um quadro organizacional que permite a sistematização dos levantamentos arqueológicos. As fraçōes mínimas de abordagem regional são as microbacias hidrográficas, que constituem unidades preferenciais de enfoque.

A partir dessa organização regional, a cartografia sistemática do Projeto tem por meta a representação de seu espaço territorial por meio de mapas (eventualmente cartas) elaborados de forma seletiva e progressiva, segundo os objetivos e prioridades conjunturais e de acordo com os padrões cartográficos vigentes.

O Plano Cartográfico do Projeto Paranapanema é dotado de flexibilidade que permite incorporar levantamentos cartográficos destinados a atender necessidades supervenientes. Nesse sentido, alinha-se perfeitamente às diretrizes do Programa.

\section{Terminologia}

São colocadas em seguida definições e conceitos relativos à matéria, que de algum modo forneceram subsídios à elaboração do Plano Cartográfico do Projeto Paranapanema.

CARTOGRAFIA: a Associação Cartográfica Internacional define Cartografia como o "conjunto de estudos e operações científicas, artísticas e técnicas, baseado nos resultados de observações diretas ou de análise de docu-

(1) O Projeto Paranapanema - Programa Regional de Pesquisas Arqueológicas - tem por objetivo o estudo das ocupaçōes indigenas pré-coloniais do trecho paulista da Bacia do Rio Paranapanema. mentação, visando a elaboração e preparação de cartas, projetos e outras formas de expressão, bem como a sua utilização" (Oliveira, 1983:97).

MAPA, CARTA E FOLHA: mapa é “a representação cartográfica dos fenômenos - naturais e humanos de uma área, dentro de um sistema de projeção e em determinada escala, de modo a traduzir, com fidelidade, suas formas e dimensōes"(Santos, 1989:1). Muitas vezes, a representação de uma área, em função de sua extensão ou da escala adotada, requer a utilização de peças cartográficas articuladas. Assim, ao conjunto dá-se o nome de carta e as peças, individualmente, sāo denominadas folhas.

CARTA BÁSICA: é a peça cartográfica plana, convencional, de grande precisão, completa, da qual derivam os mapas gerais, temáticos e especiais (Oliveira, 1983:88).

PLANTA: é a representação cartográfica plana de uma área de pequena extensāo territorial, onde a escala é constante pelo fato de não se considerar a curvatura da Terra. Desenhada em escala grande, apresenta informaçōes detalhadas.

MAPA TOPOGRÁFICO: também conhecido por planialtimétrico, inclui acidentes naturais e antrópicos, curvas de nivel e cotas altimétricas.

MAPA PLANIMÉTRICO: inclui acidentes geográficos em geral, sem mençōes altimétricas.

ESCALA: é a relação existente entre as medidas do mapa e as correspondentes dimensōes no terreno. As escalas grandes têm denominador menor (plantas); os mapas regionais, com informaçōes genéricas, têm escala pequena.

LEGENDA E CONVENÇÕES: legenda é o conjunto de informações que acompanha mapas e cartas (título, explicação de símbolos, articulação, etc.). Convençōes são simbolos utilizados para representar eventos de qualquer natureza.

NOMENCLATURA: é o sistema de referência de mapas, plantas e folhas por meio de codificação alfanumérica. 


\section{Tipologia cartográfica}

A cartografia sistemática do Projeto Paranapanema prevê a elaboração das seguintes categorias de mapas:

MAPAS GERAIS: confeccionados na escala 1:100.000 e menores (a rotina irá, todavia, situá-los preferencialmente entre as escalas de 1:500.000 e 1:1.000.000). Proporcionam informaçōes genéricas a respeito do território do Projeto e de sua organização regional. Podem apresentar algumas cotas altimétricas, rios principais, sedes e limites municipais, sítios arqueológicos isolados ou agrupamentos de sitios. Caracterizam-se como mapas de reconhecimento ou de sintese. As bases cartográficas utilizadas são as folhas topográficas do IBGE, escala 1:250.000, as Folhas da Carta do Brasil ao Milionésimo e os Mapas do Estado de São Paulo editadas pelo IGC-SP, escala 1:1.000.000.

MAPAS TEMÁTICOS: no âmbito do Plano Cartográfico do Projeto Paranapanema, os mapas temáticos se referem preferencialmente aos resultados dos enfoques interdisciplinares no campo da Arqueologia. São produzidos a partir de estudos geoarqueológicos ou bioarqueológicos. As escalas adotadas poderão ser grandes ou pequenas, de acordo com o nível de detalhamento desejado. As bases cartográficas preferenciais são as produzidas pelo IPTSP (Mapa Geológico do Estado de São Paulo, escala 1:500.000; Mapa Geomorfológico do Estado de São Paulo, escala 1:1.000.000), pelo Convênio DAEE-SP/UNESP (Carta Geológica do Estado de São Paulo, escala 1:250.000), como também aquelas obtidas por fotointerpretação (normalmente na escala aproximada de 1:25.000). Incluem-se nessa categoria perfis e blocodiagramas de interesse interdisciplinar, em qualquer escala.

MAPAS ESPECIAIS: os mapas especiais são geralmente apresentados em escala de semidetalhe ( $1: 50.000$ a 1:10.000) ou de detalhe (maiores que 1:10.000). As bases cartográficas são produzidas pelo IBGE (Carta do Brasil, escala 1:50.000), pelo IGC (Plano Cartográfico do Estado de São Paulo, escala 1:10.000) ou por meio de fotointerpretação e levantamentos de campo (escala 1:25.000 e maiores). Neste conjunto são elaborados mapas municipais de cadastramento de sitios arqueológicos, mapas de microbacias hidrográficas, mapas de sistemas microregionais e locais de sitios arqueológicos, plantas de sitios e de seus setores. Inclui-se também nessa categoria a elaboração de cortes e blocodiagramas de sitios, com assuntos exclusivamente arqueológicos.

Todos os tipos de mapas (gerais, temáticos e especiais) são organizados em séries.

\section{Sistema de referência}

O sistema de referência dos produtos cartográficos do Projeto Paranapanema concretiza-se pela adoção de uma nomenclatura adequada ao seu escopo, que se liga à aquisição seletiva e progressiva de dados, refletindo claramente $o$ andamento das pesquisas.

A nomenclatura adotada pelo Plano Cartográfico do Projeto Paranapanema, apesar de ter sido inspirada no sistema da Carta do Brasil ao Milionésimo, difere bastante dele. ${ }^{2}$ Trata-se de uma combinação de letras e números (código alfanumérico) utilizada para identificar individualmente as séries de mapas do projeto.

$O$ código tem quatro componentes separados por hifen, com a seguinte especificação:

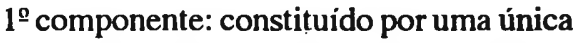
letra que designa o tipo de mapa ( $\mathrm{G}$ Geral, T - Temático, E - Especial).

$2^{2}$ componente: formado por três letras, identifica a série. Atualmente estāo codificadas as seguintes séries: Geral (GER), Regiōes (REG), Meso-Regiōes (MER), Micro-Regiōes (MIR), Geoarqueologia (GEO), Municipios (MUN), Micro-Bacias Hidrográficas (MBH), Sítios Arqueológicos (ARQ).

3o componente: sua constituiçāo varia entre códigos numéricos, alfabéticos ou alfanuméricos. Pode identificar uma unidade regional (um, dois ou três números, de acordo com a categoria regional), uma microbacia hidrográfica (quatro números), um município (três letras) ou um sítio arqueológico (três letras ou duas letras e um

(2) A Carta do Brasil ao Milionésimo resulta do compromisso do Pais para a elaboração da Carta Internacional do Mundo, na escala 1:1.000.000. Seu sistema de referência compreende fusos e séries de zonas, delimitadas por meridianos e paralelos, respectivamente. 
número), um subprograma especial de salvamento arqueológico (SALV. seguido da sigla do reservatório); sistemas micro-regionais ou locais serão identificados pelo sitio principal. ${ }^{3}$ Os mapas gerais, Série Geral, que focalizem a área total do projeto serão identificados, no nivel do terceiro componente, pela sigla PP.

$4^{9}$ componente: representa a ordem sequencial, cronológica da elaboração, no âmbito da série.

Exemplos:

G-REG-1-1, onde G - Mapa Geral, REG - Série Regiōes, 1 - Região 1. Bacia Superior, 1 - primeiro mapa da série.

E-ARQ-CM2-4, onde E - Mapa Especial, ARQ - Série Sitios Arqueológicos, CM2 - Sítio Camargo 2, 4 - quarto mapa da série.

\section{Formas de apresentação}

Os mapas do Projeto Paranapanema são elaborados, em seu formato original, em filmes de poliéster para desenho técnico, com espessura de 75 micra, disponiveis no mercado.

As opçōes para a formatação das pranchas se baseiam preferencialmente nas convençōes da $\mathrm{ABNT},{ }^{4}$ que estabelece os formatos de papéis para uso oficial, especificados de acordo com a tabela a seguir.

Formatos compostos, obtidos pela conjugação de formatos iguais ou consecutivos, são eventualmente utilizados. Como muitas vezes o formato ideal da prancha se distancia das opçōes oferecidas pela ABNT, adota-se uma solução em que pesa o caráter de flexibilidade: neste caso, a proporção da área mapeada determina a formatação da prancha de desenho.

\begin{tabular}{|c|c|c|}
\hline Formato & Altura & Comprimento \\
\hline A0 & $841 \mathrm{~mm}$ & $1.189 \mathrm{~mm}$ \\
\hline A1 & $594 \mathrm{~mm}$ & $841 \mathrm{~mm}$ \\
\hline A2 & $420 \mathrm{~mm}$ & $594 \mathrm{~mm}$ \\
\hline A3 & $297 \mathrm{~mm}$ & $420 \mathrm{~mm}$ \\
\hline A4 & $297 \mathrm{~mm}$ & $210 \mathrm{~mm}$ \\
\hline
\end{tabular}

Todos os mapas do Projeto Paranapanema deverảo apresentar, obrigatoriamente, as seguintes chamadas:

1. Identificação do mapa: o nome do mapa será precedido pela expressão Projeto Paranapanema; o subtitulo, se necessário, será colocado em seguida. A nomenclatura do mapa, de acordo com o sistema de referência, deverá estar presente; 2 . Legenda de convençōes; 3 . Escala: a escala gráfica é imprescindivel; nos originais sujeitos a redução, não deverá constar a escala numérica; 4 . Ano da execução; 5. Base cartográfica; 6. Nome do organizador (ou da equipe) e do desenhista. Em campo individualizado, deverá ser anotada a expressão PLANO CARTOGRÁFICO DO PROJETO PARANAPANEMA.

José Luiz de Morais*

\section{Referências bibliográficas}

OLIVEIRA, C. Dicionário Cartográfico. Rio de Janeiro, Fundação IBGE, 1983.

SANTOS, M.C.S.R. Manual de Fundamentos Carto- gráficos e Diretrizes Gerais Para Elaboraf̧ão de Mapas Geológicos, Geomorfológicos e Geotécnicas. São Paulo, IPT, 1989.

Recebido para publicação em 30 de agosto de 1992.

(3) Os códigos citados são obtidos na ficha de cadastramento de sitio.

(4) ABNT - Associaçào Brasileira de Normas Técnicas.
(*) Museu de Arqueologia e Etnologia da Universidade de São Paulo 